\title{
Studi tentang Motivasi ARMY Jakarta dalam Membeli Merchandise Idola (Studi Kasus Kaos Uniqlo X BT21)
}

\author{
Johanna Ruthllianie, Diah Ayu Candraningrum \\ Johanna.915160182@stu.untar.ac.id,Diahc@fikom.untar.ac.id
}

Fakultas Ilmu Komunikasi Universitas Tarumanagara

\begin{abstract}
This research attempts to adopt the individual motivation behind the decision in purchasing an idol merchandise. In addition the resources focused on the concept of consumer motivation and the consumer decision making process. The concept of motivation includes sources of motivation, divided into motivational intrinsic and motivation extrinsic. While the consumer decision-making process is divided into five steps which are recognized the need, looking for information, evaluation of decision, buying decision, and the consumer behavior after purchasing. The researcher uses a case study of the shirt Uniqlo X BT21 with qualitative method. The results of the research which is the consumer motivation lead to purchasing a Uniqlo X BT21 shirt. Parasocial interaction in fact can influence consumers to purchase merchandise. The more closely the relation between society can lead to higher motivation to purchase the needs. The collaboration between Uniqlo and BTS succeeds in attracting the fans. The results of collaboration between brand and public figures now is a strategy for creating promotional products. Entrepreneurs, who also use this strategy need to see the opportunity by using this phenomenon.
\end{abstract}

Keywords: consumer decision making process, motivation.

\begin{abstract}
Abstrak
Penelitian ini mengangkat tentang motivasi individu dalam keputusan pembelian merchandise idola. Konsep yang digunakan yaitu motivasi dan keputusan pembelian. Konsep motivasi meliputi sumber motivasi, yaitu melalui motivasi intrinsik dan motivasi ekstrinsik. Sedangkan untuk keputusan pembelian melalui lima tahapan yaitu, mengenali kebutuhan, pencarian informasi, evaluasi alternatif, keputusan pembelian dan perilaku pasca pembelian. Penelitian ini menggunakan studi kasus terhadap kaos Uniqlo X BT21 dengan metodologi kualitatif. Hasil penelitian ini yaitu motivasi yang menyebabkan pembelian kaos Uniqlo X BT21. Interaksi parasosial terbukti mampu untuk mempengaruhi pembelian merchandise. Semakin lekat sebuah hubungan parasosial, maka akan semakin tinggi motivasi minat beli. Kolaborasi yang diadakan Uniqlo dengan BTS dapat dikatakan berhasil menarik minat penggemar. Sehingga kolaborasi merek dan public figure kini merupakan sebuah strategi yang dapat dilakukan untuk mempromosikan produk. Pebisnis perlu melihat peluang yang hadir dalam fenomena tersebut.
\end{abstract}

Kata kunci: motivasi, keputusan pembelian konsumen

\section{Pendahuluan}

Korean pop atau K-Pop merupakan jenis musik yang berasal dari negeri ginseng yaitu Korea Selatan. Musik K-Pop memiliki ciri khasnya tersendiri, sehingga 
memberi warna baru bagi industri musik dunia. Proses penyebaran budaya pop Korea disebut dengan Korean Wave atau Hallyu. Korean Wave mulai berkembang di Indonesia sejak awal tahun 2000-an (Angeline, 2019).

BTS atau Bangtan Boys merupakan boyband Korea yang memulai debut pada Juni 2013. Kemunculannya banyak menyita perhatian pecinta dan penikmat musik KPop. Beranggotakan ketujuh pria yaitu RM, Jin, SUGA, j-hope, Jimin, V, dan Jungkook. Salah satu hal yang paling membuat BTS dikenal adalah karena konsep yang mereka hadirkan. (Big Hit Entertainment, 2019). Kesuksesan yang diraih BTS, tentu tidak luput dari dukungan para penggemar. ARMY merupakan sebutan bagi pecinta atau penggemar dari boy group BTS. (Siahaan, 2019).

Pada tahun 2017 LINE corporate membuat sebuah kolaborasi dengan BTS, yaitu dengan membuat stiker yang akan digambar langsung oleh BTS sendiri. Stiker tersebut kemudian diberikan nama BT21 dan dapat diunduh secara gratis oleh pengguna LINE. Mereka menamainya Tata, Mang, Koya, RJ, Shooky, Cooky, Chimmy dan Van yang merupakan robot milik Tata (Azryatiti, 2017). Salah satu kolaborasi yang dilakukan pada tahun 2019 adalah dengan Uniqlo (Uniqlo, 2019).

Uniqlo merupakan salah satu merek baju asal Jepang yang sudah tersebar di seluruh dunia. (Uniqlo, 2019). Kesuksesan BTS yang mendunia, menjadikan Uniqlo menawarkan kerjasama dengan BTS yaitu dengan karakter BT21 untuk membuat kaos dengan masing-masing karakter (Bela, 2019).

Pada saat perilisan kaos tersebut para ARMY rela meluangkan waktu mereka untuk mengantri di depan toko Uniqlo. Antrian yang panjang dan membludak diatasi Uniqlo dengan pemberlakuan kupon. Harga satuan kaos tersebut dibandrol dengan harga Rp. 149.000,00 (Bela, 2019).

Kotler dan Keller (2012:498) menyatakan bahwa komunikasi pemasaran adalah sarana yang digunakan perusahaan dalam upaya untuk menginformasikan, membujuk, dan mengingatkan konsumen baik secara langsung maupun tidak langsung tentang produk dan merek yang mereka jual.

Menurut Armstrong (2009), menyatakan bahwa motif adalah alasan yang mendasari perilaku. Motivasi berkaitan dengan kekuatan, arah perilaku, dan faktorfaktor yang mempengaruhi seseorang untuk berperilaku dengan cara tertentu. mereka (Priansa, 2017).

Stever (2013), interaksi parasosial adalah respon yang diberikan seseorang terhadap figur media di televisi seakan-akan figur media tersebut benar benar ada dalam ruangan tempat dia berada (Stever, 2013).

Keputusan pembelian tersebut melalui lima tahapan yaitu mengenali kebutuhan, mencari informasi, evaluasi alternatif, keputusan pembelian, perilaku pasca pembelian (Kotler \& Keller, 2012).

Motivasi pula yang mendorong para penggemar BTS untuk melakukan pembelian untuk kaos Uniqlo X BT21 hingga rela mengantri panjang. Pada penelitian ini, penulis akan menelaah lebih jauh motivasi para penggemar BTS terhadap pembelian kaos Uniqlo X BT21.

\section{Metode Penelitian}

Pendekatan penelitian yang akan digunakan merupakan pendekatan kualitatif. Menurut Strauss dan Corbin (2007), pendekatan kualitatif merupakan jenis penelitian yang temuannya tidak diperoleh melalui prosedur statistik atau bentuk hitungan lainnya. (Nugrahani, 2014). 
Metode penelitian yaitu studi kasus merupakan penelitian tentang manusia dapat suatu kelompok, organisasi maupun individu, peristiwa, latar, tujuan penelitian yang mendapat gambaran mendalam tentang kasus yang akan diteliti. (Sujarweni, 2019).

Subjek penelitian adalah orang dalam latar yang memahami informasi atas objek yang akan diteliti (Bungin, 2010). Subjek penelitian yaitu ARMY Jakarta pembeli kaos Uniqlo X BT21. Objek penelitian merupakan masalah yang akan diteliti (Bungin, 2010). Objek penelitian yaitu kaos Uniqlo X BT21.

Metode pengumpulan data yaitu dengan menggunakan sumber primer dan sumber sekunder. Sumber primer terdiri wawancara dan observasi. Wawancara lainnya (Sujarweni, 2019). Wawancara dilakukan dengan tiga orang informan yaitu, Lusia Savitri Setyo Utami dan Florentina Melani Chandra selalu ARMY BTS yang ikut mengantri langsung pada saat penjualan kaos Uniqlo X BT21, dan Ferren Santica selaku pembeli kaos Uniqlo X BT21 melalui jasa titip. Observasi yaitu suatu kegiatan untuk mendapatkan gambaran nyata terhadap suatu peristiwa atau kejadian tertentu (Bungin, 2010). Observasi dilakukan dengan melakukan pertemuan langsung dengan ketiga ARMY yang membeli kaos tersebut. Sumber sekunder melalui studi kepustakaan yaitu kajian dari bahan dokumenter yang tertulis bisa berupa buku teks, surat kabar, majalah, surat-surat, film, catatan harian, naskah, artikel, pikiran seseorang yang tertuang dalam sebuah buku, atau naskah-naskah yang terpublikasikan.

Teknik pengolahan dan analisis data yaitu reduksi data, penyajian data, penyimpulan dan verifikasi, kesimpulan akhir (Sujarweni, 2019). Teknik keabsahan data yaitu dengan triangulasi dengan sumber data. Triangulasi sumber merupakan teknik mendapatkan kebenaran akan suatu informasi dengan memperoleh data dari berbagai sumber (Gunawan, 2014). Dalam penelitian ini penulis mendapatkan informasi dengan melakukan wawancara dengan dua (2) sumber yaitu, Muhammad Puja Haikal Afdhal selaku Assistant Store Manager Uniqlo cabang Galaxy Mall Surabaya, dan Untung Subroto Dharmawan sebagai pengamat hubungan parasosial yang terjadi antara idola dan penggemar.

\section{Hasil Temuan dan Diskusi}

\section{Sumber Motivasi Konsumen}

\section{Motivasi Intrinsik}

Motivasi intrinsik muncul karena motif yang timbul dalam diri sendiri. Motif ini mampu aktif dan berfungsi tanpa adanya rangsangan dari luar. Faktor yang mendorong konsumen untuk melakukan pembelian adalah (Priansa, 2017) :

a. Minat : konsumen cenderung terdorong melakukan kegiatan yang sesuai dengan minat yang diinginkan. ARMY merupakan penggemar memiliki minat yang besar terhadap BTS. Kaos Uniqlo X BT21 merupakan karya yang dibuat oleh idola mereka yaitu BTS. Sehingga mereka menganggap bahwa dengan membeli kaos tersebut salah satu bentuk pembuktian minat mereka terhadap BTS..

b. Sikap Positif : konsumen yang mempunyai sikap positif terhadap suatu pekerjaan rela ikut dan terlibat dalam kegiatan tersebut, serta akan mengerjakannya dengan baik. Sikap positif yang dirasakan ARMY setelah membeli kaos yaitu, merasa telah diakui sebagai bagian dari komunitas para penggemar BTS. Selain itu mereka merasa bahwa BTS juga membawa dampak positif bagi diri mereka, yaitu sebagai inspirasi dan penyemangat. 
c. Kebutuhan: konsumen memiliki kebutuhan tertentu dan berupaya untuk memenuhinya dengan melakukan berbagai aktivitas dan kegiatan. Selain itu kebutuhan juga dapat dikaitkan dengan kaos atau pakaian yang merupakan kebutuhan primer manusia. Hal tersebut merupakan salah satu alasan dalam pembelian kaos Uniqlo X BT21. Pembelian kaos tersebut dinilai lebih berguna dibanding dengan pembelian merchandise Kpop lainnya.

\section{Motivasi Ekstrinsik}

Motivasi ekstrinsik muncul karena motif yang timbul luar diri sendiri. Motif ini mampu aktif dan berfungsi dengan adanya rangsangan dari luar. Faktor yang mendorong konsumen untuk melakukan pembelian adalah (Priansa, 2017):

a. Motivator: berkaitan dengan kemampuan daya beli, kebutuhan akan prestise, kebutuhan eksistensi dan lain sebagainya. Pada penelitian ini pendorong terjadinya pembelian terbesar adalah BTS. Kemampuan pembelian yaitu menyangkut masalah harga yang ditawarkan. Alasan pembelian kaos Uniqlo X BT21 karena harganya yang bagi mereka cukup terjangkau yaitu Rp. 149.000,00. Hal yang melatarbelakangi penggemar menyatakan hal tersebut yaitu karena harga baju BT21 lainnya biasanya lebih mahal. Kebutuhan akan prestise yaitu merupakan bentuk keinginan diperlakukan istimewa atau berbeda dibanding orang sekitarnya. Kebutuhan eksistensi yaitu penggemar merasa puas sudah membeli sebuah karya yang dikeluarkan oleh idolanya.

b. Stimulus: stimulus yang berasal dari perusahaan akan mendorong konsumen untuk bersikap dan berperilaku. Stimulus atau pendukung dalam hal ini yaitu Uniqlo. Uniqlo merupakan perusahaan asal Jepang yang sudah cukup dikenal oleh berbagai kalangan. Salah satu alasan pembelian yang dilakukan oleh penggemar yaitu kualitas baju yang dikeluarkan Uniqlo yang terkenal dengan kualitas bahannya. Mereka berpendapat bahwa baju yang diproduksi oleh Uniqlo selama ini nyaman dan sesuai dengan harga. Bagi mereka harga Rp 149.000,00 sangat layak untuk dibeli. Disamping kualitas yang sudah diakui baik, harga jual yang ditawarkan dinilai cukup wajar. Alasan selanjutnya yaitu karena di Indonesia belum ada tempat atau toko yang menjual barang official Kpop merchandise seperti di negara Asia lainnya. Jika ingin mendapatkan merchandise official, para penggemar harus membeli langsung ke Korea atau melalui jasa titip.

\section{Interaksi Parasosial}

Stever (2013), interaksi parasosial yaitu respon yang diberikan oleh seseorang terhadap figur yang digemari melalui media televisi, seakan-akan figur tersebut benar benar ada dalam ruangan tempat dia berada (Stever, 2013). Semakin tinggi tingkat parasosial maka penggemar akan semakin ingin membeli merchandise idolanya. Tingkatan parasosial dibagi menjadi tiga yaitu mild untuk ringan, moderate untuk sedang dan savere untuk berat. Dalam kasus ini tingkat penggemar yang melakukan pembelian yaitu moderate menuju savere.

\section{Keputusan Pembelian}

Tugas pemasar adalah memahami perilaku pembeli pada tiap-tiap tahap dan pengaruh dari tahap tersebut. Secara terperinci tahap-tahap tersebut diuraikan sebagai berikut (Kotler dan Keller, 2012) : 


\section{Mengenali Kebutuhan}

Proses membeli diawali dengan adanya masalah kebutuhan yang harus dipenuhi. Kebutuhan disebabkan oleh rangsangan internal dan eksternal. Masalah dalam hal ini yaitu adanya kaos kolaborasi antara Uniqlo dan BT21. ARMY merasa perlu mendapatkan kaos tersebut karena kebutuhan atribut sebagai seorang penggemar.

\section{Pencarian Informasi}

Seorang konsumen memiliki minat akan terdorong untuk mencari informasi lebih banyak. Sumber informasi bisa didapatkan melalui orang terdekat, iklan, media massa dan media sosial. Informasi tambahan bisa didapat melalui media sosial resmi Uniqlo, seperti Line, Twitter, Instagram, Facebook maupun website. Informasi tersebut meliputi hari dan tanggal waktu kaos akan dijual. Kemudian juga mencari gambar dari desain masing-masing kaos.

\section{Evaluasi Alternatif}

Tahap ini konsumen mengevaluasi dan memproses informasi tentang pilihan produk dan merek untuk membuat keputusan akhir pembelian. Konsumen menentukan desain, warna, dan jumlah kaos yang akan dibeli. Pembeli akan menentukan karakter animasi BT21 dan warna kaos yang disukai.

\section{Keputusan Pembelian}

Konsumen membentuk preferensi terhadap merek-merek yang terdapat pada perangkat pilihan. Keputusan pembelian yang dipilih ARMY berbeda-beda. Beberapa memutuskan untuk mengantri langsung pada saat peluncuran kaos tersebut. Sementara ARMY yang berhalangan hadir akan membeli melalui jasa titip.

\section{Perilaku Sesudah Pembelian}

Sesudah pembelian terhadap suatu produk yang dilakukan konsumen akan mengalami beberapa tingkat kepuasan atau ketidakpuasan. Setelah membeli kaos penggemar akan melihat dan mengenakannya secara langsung. Hal tersebut menyebabkan munculnya perilaku sesudah pembelian. ARMY mengaku puas atas kualitas kaos yang mereka dapatkan, karena bahan Uniqlo yang nyaman untuk dipakai sehari-hari. ARMY yang mengantri langsung merasa senang karena bisa mendapatkan kaos yang dia inginkan dengan harga Rp. 149.000,00. Sementara ARMY yang melalui jasa titip membeli kaos tersebut dikenakan biaya jasa titip sebesar Rp. 51.000,00, sehingga harga kaos tersebut menjadi Rp. 200.000,00.

Penggemar membutuhkan sebuah identitas yang menunjukkan kecintaan atau kekaguman terhadap idolanya. Sehingga sering kali penggemar membeli atribut untuk menunjukan hal kegemarannya. Karena daya beli penggemar yang tinggi dan simultan, hal ini yang melatarbelakangi maraknya perusahaan yang menjual atribut K-Pop. Penggemar K-Pop cenderung lebih konsumtif dibanding penggemar genre musik lain. Hal tersebut dibuktikan dari larisnya penjualan merchandise K-Pop baik yang official maupun yang unofficial.

Menurut Lingga, Setyanto dan Utami (2018), penggemar dapat dikatakan sebagai individu yang berlebihan, konsumtif, dan terobsesi kepada idolanya. Individu yang tidak terlibat komunitas penggemar biasanya tidak akan mengerti isi komunikasi yang sedang berlangsung dalam komunitas penggemar tersebut (Lingga, Setyanto, \& Utami, 2018). 


\section{Kesimpulan}

Kerjasama yang terjalin antara merek dan public figure terbukti saat ini membawa dampak yang baik bagi pebisnis. Merek mencari sebuah partner yang dapat menaikan penjualan produknya. Hal ini dapat dibuktikan dalam kasus kerjasama antara BTS dan Uniqlo. BTS yang sebelumnya telah membuat karakter animasi BT21 dianggap mampu menarik minat penggemar untuk membeli kaos Uniqlo X BT21. Pada saat perilisan kaos tersebut terbukti antusias penggemar untuk membeli kaos tersebut. Penggemar rela antri dan sebagian lainnya membeli melalui jasa titip.

Parasosial merupakan hubungan sepihak yang dirasakan penggemar terhadap idolanya. Semakin seseorang merasa lekat dengan idola mereka, maka akan timbul adanya keinginan untuk diakui sebagai seorang penggemar sejati. Hal tersebut yang mempengaruhi tingkat motivasi pembelian terhadap merchandise. Penggemar membutuhkan atribut sebagai simbol kecintaan terhadap idolanya. Setelah terjual habisnya kaos Uniqlo X BT21, Uniqlo dianggap telah sukses dalam menjalin kerjasama dengan BTS.

\section{Ucapan Terimakasih}

Ucapan terima kasih diberikan kepada Fakultas Ilmu Komunikasi Universitas Tarumanagara, kepada narasumber yang telah membantu, keluarga serta teman-teman yang selalu memberikan dukungan kepada penulis, dan kepada semua pihak yang telah mendukung dan membantu penelitian ini. Tanpa bantuan dari semua orang yang terlibat dalam penelitian ini, penelitian ini tidak dapat berjalan dengan lancar. Penulis sadar bahwa penelitian ini masih memiliki banyak kekurangan. Namun penulis berharap penelitian ini dapat berguna dan bermanfaat baik dalam akademis maupun praktik.

\section{Daftar Pustaka}

Angeline, N. (2019, Januari 20). Dicap Alay hingga Jadi Tren, Begini Perkembangan K-Pop dari Masa ke Masa. Retrieved September 10, 2019, from Hot.detik.com: https://hot.detik.com/kpop/d-4392910/dicap-alay-hingga-jaditren-begini-perkembangan-k-pop-dari-masa-ke-masa

Azryatiti, T. A. (2017, September 27). BT21 - BTS Rilis Sticker LINE Kreasi Mereka Sendiri Loh! Kenalan Sama Karakter Imutnya Berikut Ini. Retrieved September 17, 2019, from tribunstyle.com: https://style.tribunnews.com/2017/09/27/bt21-bts-rilis-sticker-line-kreasimereka-sendiri-loh-kenalan-sama-karakter-imutnya-berikut-ini?page $=4$

Bela. (2019, Juni 21). Diluncurkan Hari Ini, Kaos Uniqlo X BT21 Sudah Sold Out. Retrieved September 10, 2019, from indozone.com: https://www.google.com/url?sa=i\&source=images $\& c d=\& c a d=r j a \& u a c t=8 \& v$ ed=0ahUKEwiy8syC9MfkAhVNF6wKHUMKCmUQMwg5KA0wDQ\&url= https $\% 3 \mathrm{~A} \% 2 \mathrm{~F} \%$

Big Hit Entertainment. (2019). About BTS. Retrieved September 10, 2019, from ibighit.com: https://ibighit.com/bts/eng/

Bungin, B. (2010). Metode Penelitian Kualitatif. Jakarta: Rajawali Pers. Retrieved September 19, 2019 
Gunawan, I. (2014). Metode Penelitian Kualitatif. Jakarta: Bumi Aksara. Retrieved September 20, 2019

Kotler, P., \& Keller, K. L. (2012). Manajemen Pemasaran (12 ed.). Jakarta: Erlangga. Retrieved September 212019

Lingga, L., Setyanto, Y., \& Utami, L. S. (2018). Komunikasi Antarpribadi Sesama Penggemar dalam Fandom (Studi pada Penggemar dalam Fandom BTS di Jakarta. Koneksi. Retrieved January 10, 2020

Nugrahani, F. (2014). Metode Penelitian Kualitatif. Surakarta. Retrieved Oktober 1, 2019

Priansa, D. J. (2017). Perilaku Konsumen dalam Persaingan Bisnis Kontemporer. Bandung: Alfabeta. Retrieved September 16, 2019

Siahaan, S. (2019, Oktober 08). Tokopedia.com. Retrieved Desember 02, 2019, from Fakta Unik BTS ARMY, Fandom terbesar di Dunia Kpop: https://www.tokopedia.com/blog/profil-bts-ARMY/

Stever, G. S. (2013). Mediated vs Parasocial Relationships: An attachment perspective. Journal of Media Psychology, 17. Retrieved December 10, 2019

Sujarweni, W. (2019). Metodologi Penelitian. Yogyakarta: Pustaka Baru. Retrieved October 8, 2019

Uniqlo. (2019). Retrieved September 10, 2019, from uniqlo.com: http://www.uniqlo.com/id/corp/pressrelease/2018/

Uniqlo. (2019, Juni 18). UNIQLO akan Meluncurkan UT yang Menampilkan Karakter Brand BT21. Retrieved September 10, 2019, from uniqlo.com: http://www.uniqlo.com/id/corp/pressrelease/2019/ 